\title{
Non-invasive measurement of faecal glucocorticoid metabolites in Upland Geese Chloephaga picta
}

\author{
Martina Koch · Erich Möstl · Hanspeter W. Steinmetz • \\ Marcus Clauss $\cdot$ Juan F. Masello $\cdot$ Petra Quillfeldt
}

Received: 25 April 2008 / Revised: 19 September 2008 / Accepted: 28 September 2008 / Published online: 22 October 2008

(C) The Author(s) 2008. This article is published with open access at Springerlink.com

\begin{abstract}
Glucocorticoid (GC) hormones rise in response to stressors, including natural events including weather or predator presence, and human activities, such as hunting, scientific research or recreational visits. However, because blood sampling itself causes stress and is dangerous or even impossible in some wildlife species, feedback-free methods for GC determination are needed to assess stress in these animals. Faecal GC analyses have thus gained interest. Here, we validate a non-invasive method to estimate the physiological stress in the Upland goose Chloephaga picta. An adrenocorticotropin hormone (ACTH) challenge was conducted in captive adults (female and male), and droppings were collected before, during and after the experiment. Corticosterone metabolite (CM) secretion in response to the ACTH challenge was measured with several enzyme immunoassays (EIA) to find the most appropriate test. We used CM levels during the periods before and after the experiment as control data. An EIA for 11-oxoetiocholanolone achieved the highest response to the ACTH challenge and also reflected a stress response to unfamiliar environ-
\end{abstract}

M. Koch

Institute of Biology, Humboldt-Universität zu Berlin, Invalidenstraße 43, 10115 Berlin, Germany

E. Möstl

Institut für Biochemie, Veterinärmedizinische Universität,

Veterinärplatz 1, 1210 Vienna, Austria

H. W. Steinmetz $\cdot$ M. Clauss

Clinic for Zoo Animals, Exotic Pets and Wildlife,

Vetsuisse Faculty, University of Zurich, Zurich, Switzerland

J. F. Masello · P. Quillfeldt ( $\square)$

Max Planck Institute for Ornithology, Vogelwarte Radolfzell,

Schlossallee 2, 78315 Radolfzell, Germany

e-mail: petra.quillfeldt@gmx.de ment. Furthermore, CM concentrations of dry samples were highly correlated with the corresponding non-dried (frozen) samples. The data suggest that this method is appropriate to measure the stress in Upland geese, and that samples can be stored either frozen or dry form.

Keywords Chloephaga picta Conservation biology . Corticosterone metabolites · Non-invasive endocrine monitoring $\cdot$ Stress

\section{Introduction}

In addition to natural environmental disturbances, human activities, such as tourism (Fowler 1999; Müllner et al. 2003), related leisure activities (Creel et al. 2002; Watson and Moss 2004), as well as research activities that include handling of wildlife can bear a negative pressure on wildlife. Non-invasive methods originally developed for research into animal welfare (Wasser et al. 2000; Möstl and Palme 2002) have become a tool in ecology and conservation biology (Nakagawa et al. 2003; Baltic et al. 2005; Walker et al. 2005; Thiel et al. 2008). Enzyme immunoassays (EIA) that measure faecal glucocorticoid (GC) metabolites have enabled researchers to associate behavioural changes in free-ranging animals with the physiological costs they generate and to quantify the impact of natural or anthropogenic-induced stress (Kotrschal et al. 1998; Dehnhard et al. 2003; Quillfeldt and Möstl 2003; Tempel and Gutiérrez 2004).

Unlike blood, faecal samples can be collected easily without unduly stressing the animals. Faeces also have the advantage of enabling time-integrated measures of GC. However, most native GCs are metabolised in a speciesspecific manner before excretion, and resulting GC metabo- 
lites can vary amongst different species ( Möstl et al. 2005). Therefore, assays for GC metabolites need to be validated for each species. In the present study, we validated an EIA for faecal corticosterone metabolite (CM) from Upland geese Chloephaga picta using an adrenocorticotropin hormone $(\mathrm{ACTH})$ challenge.

Upland geese, also known as Magellan geese, belong to the "sheldgeese" (Tadornini) and are widespread in the Falkland Islands/Islas Malvinas, as well as on the South American mainland. Females and males are slightly dimorphic with regard to size, but significantly dimorphic in their plumage (Summers 1983; Summers and McAdam 1993). At New Island in the Falkland Islands/Islas Malvinas, which is managed as a nature reserve, the number of Upland geese seems to be limited by the high population density (Quillfeldt et al. 2005). In other parts of their range though, there is a considerable uncertainty as to their conservation status. They are hunted intensely, and data are urgently needed to determine their population status. Faecal $\mathrm{CM}$ analysis will be a valuable non-invasive tool for studies on of potential stressors, such as increased interactions with humans and response to local changes in population densities.

The aim of this study was to establish an appropriate EIA to measure faecal samples in this species and to compare the storage methods. We do this by measuring $\mathrm{CM}$ secretion in response to an ACTH challenge, and use CM levels during the periods before and after the experiment as control data.

\section{Methods}

ACTH challenge and experimental setup

One male and one female Upland goose of the previous years' offspring of the Zurich Zoological Garden were used in the experiment, under permit by the Department of Veterinary Medicine (Kantonales Veterinäramt). Both were about 9 months old, had grown their juvenal plumage and reached adult body mass. Prior to the experiment, they where kept together with another female sibling in an outdoor aviary $(6 \times 4 \mathrm{~m})$, enriched with shrubs and a water basin $(1 \times 1 \mathrm{~m})$. For the study, the two individuals were separately kept in opposing indoor cages in the quarantine station separated by a corridor (cage of female: $2.4 \times 3 \mathrm{~m}$; male: $4 \times 3 \mathrm{~m}$ ). The cages had tiled floors, a lattice front with a door facing the corridor, artificial light and constant temperature $\left(\sim 20^{\circ} \mathrm{C}\right)$. We added logs and a plastic water bowl $(60 \times 80 \mathrm{~cm})$. Water and food (duck pellets, a grain mixture and lettuce) were provided ad libitum. The acoustic background in the quarantine station consisted of a female Indian lion Panthera leo persica, one Madagascar crested ibis Lophotibis cristata, 10 Madagascar teal Anas bernieri and three Meller's Ducks Anas melleri. The birds remained in the indoor cages from 28 February until 6 March 2007. After a habituation period of ca. 2 days, the birds fed regularly and defecated one to two semi-liquid droppings approximately every $30 \mathrm{~min}$.

To obtain control (pre-treatment phase) data and establish the levels of naturally occurring CM concentrations, faecal samples were collected hourly during $41 \mathrm{~h}$ before the adrenocorticotropic hormone (ACTH) challenge, with 7-h breaks during the two nights.

On 2 March 2007 at 08:10 and at 08:14 hours, the two geese received an intramuscular injection of $0.25 \mathrm{mg}$ of ACTH analogue (Synacthen; Novartis Pharma AG, Basel, Switzerland). The handling lasted less than $3 \mathrm{~min}$. Faecal samples were collected continuously $1 \mathrm{~h}$ before and $4 \mathrm{~h}$ after injection and then hourly during the following $21 \mathrm{~h}$ ("post-treatment phase I"), with a 7-h break during the night after the treatment. On the fourth day, the female was moved into the cage of the male and faecal samples were taken hourly during the following $78 \mathrm{~h}$ (post-treatment phase II), with a 12-13-h break during the three nights.

All samples were immediately stored at $-20^{\circ} \mathrm{C}$ until analysed, and the cages were cleaned with water every morning by the keepers and several times during the day by the sample collector.

\section{Extraction of the excreted CM}

A subsample of $0.25 \mathrm{~g}$ of each fresh faecal sample was mixed $0.75 \mathrm{ml}$ double-distilled water followed by $1.5 \mathrm{ml}$ methanol and vortexed for $30 \mathrm{~min}$. After centrifugation $(2500 \mathrm{~g}, 10 \mathrm{~min})$, the supernatant was transferred to a new tube and used for the analyses with the various EIA described below.

To test the influence of drying on samples, a subsample of $0.25 \mathrm{~g}$ of each dropping collected between the injection and the following $10 \mathrm{~h}$ was dried using an STERIS Lyovac GT$2 \mathrm{E}$ freeze dryer. As the dry mass content of faeces typically amounts to $25 \%$ (the remaining $75 \%$ being water), we compensated for the water content lost during drying by mixing dried samples with $1 \mathrm{ml}$ double-distilled water and $1.5 \mathrm{ml}$ methanol before vortexing for $30 \mathrm{~min}$. The higher volume of water compared to fresh samples was used to compensate for the liquid in the fresh samples and keep the concentration of methanol in the extraction approximately constant.

All concentrations are given in nanogram per gram wet weight, assuming a constant water content. Because the actual water content may differ between samples, the final concentration between dry and wet samples cannot be compared directly, but a correlation between the corresponding dry and wet samples would indicate that both methods yield comparative results. 


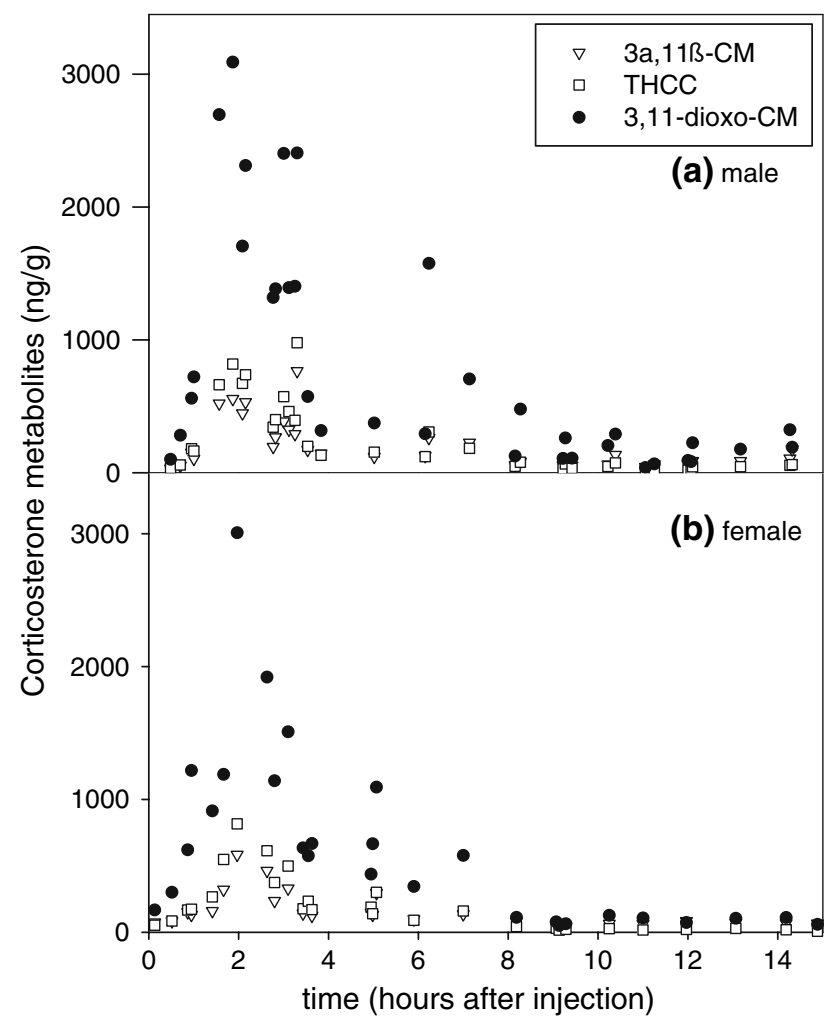

Fig. 1 Response to ACTH challenge in a male and a female Upland goose at the Zurich Zoological Garden, showing corticosterone metabolites measured in faecal samples with three different enzyme immunoassays: $11 \beta$-hydroxyetiocholanolone-EIA $(3 \alpha, 11 \beta$-CM), 11-oxoetiocholanolone-EIA (3,11-dioxo-CM) and THCC tetrahydrocorticosterone-EIA

Immunoreactivity of $\mathrm{CM}$ and biological validation of assays

An array of different, previously established EIAs was tested on the samples of the zoo to select the one best suited for Upland geese: $\mathrm{CM}$ of the series with a $5 \beta$ structure was measured using group-specific assays. The assays crossreacted either with a $3 \alpha, 11 \beta$-structure $(3 \alpha, 11 \beta$-CM, Frigerio et al. 2004), a 3,11-dioxo-structure (3,11-dioxo-CM, Möstl et al. 2002) or with tetrahydrocorticosterone (THCC, Quillfeldt and Möstl 2003; Nakagawa et al. 2003) and closely related molecules. We used $11 \beta$-hydroxyetiocholanolone $(3 \alpha, 11 \beta,-\mathrm{CM}), \quad 11$-oxoetiocholanolone $(3,11$ dioxo-CM) and tetrahydrocorticosterone as standards. As the assays are group specific, the results of the test systems have to be considered as "standard equivalents". Detailed descriptions of the different EIAs and their procedures are given in the articles cited above.

After extraction, $20 \mu \mathrm{l}$ aliquots were transferred into microtiter plates and measured using the above-mentioned assays. First, the three different EIAs were applied to the samples of both individuals collected after the injection
Table $1 \mathrm{CM}$ concentrations of two captive Upland geese at Zurich Zoological Garden determined with the 11-oxoetiocholanolone-EIA in nanogram per gram wet weight

\begin{tabular}{lll}
\hline Period & Male & Female \\
\hline Pre-treatment & $202.0(117.8-439.8)^{\mathrm{a}}$, & $115.7(82.1-166.4)^{\mathrm{a}}$, \\
period & $n=36$ & $n=31$ \\
Treatment period & Max. $3090.6 \mathrm{ng} / \mathrm{g}$ & Max. $3007.6 \mathrm{ng} / \mathrm{g}$ \\
Post-treatment & $182.8(108.9-261.1)^{\mathrm{a}}$, & $106.2(72.5-111.9)^{\mathrm{a}}$, \\
period I & $n=22$ & $n=14$ \\
Post-treatment & $87.4(61.0-118.4)^{\mathrm{b}}$, & $329.1(236.7-527.1)^{\mathrm{b}}$, \\
period II & $n=35$ & $n=28$ \\
Kruskal-Wallis & $H=26.0, d f 2$, & $H=26.2, d f 2$, \\
ANOVA & $P<0.001$ & $P<0.001$
\end{tabular}

For the treatment period (until $8 \mathrm{~h}$ after injection), we give the maximum value measured in a single sample. For non-treatment periods, the following data are given: median, $(25 \text { and } 75 \% \text { percentiles })^{\text {group, }}$ sample size. To compare between the three non-treatment periods for each individual, we used Kruskal-Wallis ANOVAs on ranks, and to isolate the group or groups that differ from the others we use a multiple comparison procedure (Dunn's method), and indicate groups with superscript letters

(treatment). Second, as the 11-oxoetiocholanolone-EIA showed the highest amounts of immunoreactive substances in the extracts, it was chosen for analysing the remaining samples (pre-, post-treatment and dried samples). 11-oxoetiocholanolone-EIA analyses were carried out on duplicate samples, and in the case of unmatched samples, the analysis was repeated. The inter-assay variation was $14.4 \%$.

\section{Results}

Response to ACTH challenge

The application of the ACTH analogue resulted in an increase in faecal CM for both female and male. The CM concentration reached the maximum after $90 \mathrm{~min}$ in the male and after $2 \mathrm{~h}$ in the female after the ACTH challenge (Fig. 1; Table 1). The concentration decreased again during the following hours, reaching baseline values $8 \mathrm{~h}$ after the injection (Fig. 1).

The 11-oxoetiocholanolone-EIA showed the highest immunoreactive concentrations, while the tetrahydrocorticosterone-EIA and the $11 \beta$-hydroxyetiocholanolone-EIA also yielded a clear difference between baseline and maximum values (Fig. 1).

$\mathrm{CM}$ from the extracts of corresponding frozen and dried faecal samples from the zoo animals analysed with the 11oxoetiocholanolone-EIA were highly correlated (Spearmann correlation: $R_{40}=0.914, P<0.001$ ). 


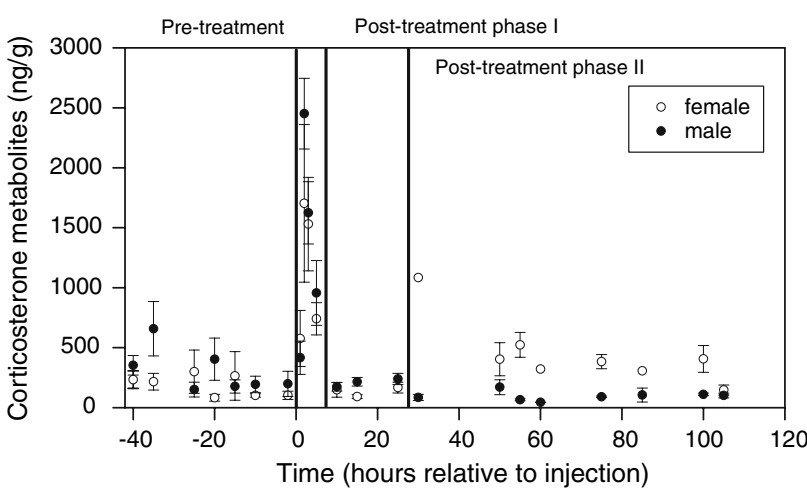

Fig. $2 \mathrm{CM}$ concentrations in faecal samples of a male and a female Upland goose at the Zurich Zoological Garden, measured with an 11-oxoetiocholanolone-EIA. The experimental periods include: pre-treatment adaptation $(41 \mathrm{~h})$ to the individual indoor cages, treatment period ( $8 \mathrm{~h}$ after the injection of an ACTH analogue), post-treatment phase I $(18 \mathrm{~h})$ in the accustomed individual indoor cage, post-treatment phase II $(61 \mathrm{~h})$ jointly in the indoor cage which previously housed the male only

\section{Response to unfamiliar environment}

CM values differed between adaptation periods in unfamiliar environments outside of the treatment period: pre-treatment phase of $41 \mathrm{~h}$ to the individual indoor cages, posttreatment period I of $18 \mathrm{~h}$ in the accustomed individual indoor cage, post-treatment period II of $61 \mathrm{~h}$ which previously housed the male only (Fig. 2; Table 1). Although the male became progressively more adapted and reached very low CM levels in the post-treatment period II (Table 1), the female had a strong rise in faecal $\mathrm{CM}$ in this period after her change to the males' cage (Fig. 2; Table 1).

\section{Discussion}

The adrenocortical response to the ACTH challenge was measured successfully by EIA in the faecal samples of Upland geese; thus, providing a non-invasive tool to detect changes in hormone levels in these geese. The 11-oxoetiocholanolone-EIA measured the highest peak values of CM in faeces of Upland geese and seems to be considerably more sensitive than the other EIAs that were tested. This EIA was originally designed to detect excreted GC metabolites in ruminants (Möstl et al. 2002). The tetrahydrocorticosterone-EIA also performed very well and may be a feasible alternative to the 11-oxoetiocholanolone-EIA if this is not obtainable. Previously, the tetrahydrocorticosterone-EIA was successfully applied in birds such as Wilson's storm-petrels (Oceanites oceanicus, Quillfeldt and Möstl 2003) and Adélie penguins (Pygoscelis adeliae, Nakagawa et al. 2003). The present findings differ from those obtained in a study of Greylag geese Anser anser (Frigerio et al.
2004) where the $3 \alpha, 11 \beta$-CM EIA gave the best results. Thus, even species that are relatively closely related and have comparable feeding habits can differ in their GC metabolism.

Our analysis of the response to a transfer to an unfamiliar environment (cage) supported the test validation by the ACTH challenge. Individual responses to these stressful situations, as measured with the 11-oxoetiocholanolone-EIA, were in line with our expectations. Both birds had higher $\mathrm{CM}$ concentrations in the faeces during the first hours after catching and handling and transfer to an unfamiliar cage. Recapture and transfer to the cage of the male further resulted in high values of the female during the post-treatment period II. After transfer, the female may have been affected by dominant behaviour by the male, which was well adapted at this time according to the CM measurements. Furthermore, the surroundings of the male's cage were also unfamiliar to her, especially the visual contact with the Indian lion in a cage diagonally opposite, which the male was already accustomed to.

The drying of faecal samples did not seem to have a negative influence on the results of CM measurements, and the good correlation between dry and frozen samples indicates that collecting droppings and subsequent drying might be the easiest way to operate during fieldwork.

Acknowledgments We are grateful to A. Kuchar who carried out the EIA, and M. Binz, A. Sidler, U. Romer for practical help and advice. The Zurich Zoological Garden provided logistical support. We thank anonymous referees who helped to improve the manuscript. This study was partly funded by grants from DFG, Germany (Qu 148-1 ff) and carried out according to the current laws of Switzerland, under permission of the Department of Veterinary Medicine, canton Zurich (Kantonales Veterinäramt).

Open Access This article is distributed under the terms of the Creative Commons Attribution Noncommercial License which permits any noncommercial use, distribution, and reproduction in any medium, provided the original author(s) and source are credited.

\section{References}

Baltic M, Jenni-Eiermann S, Arlettaz R, Palme R (2005) A non-invasive technique to evaluate human-generated stress in black grouse. Ann N Y Acad Sci 1046:81-95

Creel S, Fox JE, Hardy A, Sands J, Garrott B, Peterson RO (2002) Snowmobile activity and glucocorticoid stress responses in wolves and elk. Conserv Biol 16:809-814

Dehnhard M, Schreer A, Krone O, Jewgenow K, Krause M, Grossmann R (2003) Measurement of plasma corticosterone and fecal glucocorticoid metabolites in the chicken (Gallus domesticus), the great cormorant (Phalacrocorax carbo), and the goshawk (Accipiter gentilis). Gen Comp Endocrinol 131:345-352

Fowler GS (1999) Behavioral and hormonal responses of Magellanic penguins, Spheniscus magellanicus to tourism and nest site visitation. Biol Conserv 90:143-149

Frigerio D, Dittami J, Möstl E, Kotrschal K (2004) Excreted corticosterone metabolites co-vary with ambient temperature and air 
pressure in male Greylag geese (Anser anser). Gen Comp Endocrinol 137:29-36

Kotrschal K, Hirschenhauser K, Möstl E (1998) The relationship between social stress and dominance is seasonal in greylag geese. Anim Behav 55:171-176

Möstl E, Palme R (2002) Hormones as indicators of stress. Domest Anim Endocrinol 23:67-74

Möstl E, Maggs JL, Schrötter G, Besenfelder U, Palme R (2002) Measurement of cortisol metabolites in faeces of ruminants. Vet Res Commun 26:127-139

Möstl E, Rettenbacher S, Palme R (2005) Measurement of corticosterone metabolites in birds' droppings: an analytical approach. Ann N Y Acad Sci 1046:17-34

Müllner A, Linsenmair E, Wikelski M (2003) Exposure to ecotourism reduces survival and affects stress response in hoatzin chicks (Opisthocomus hoazin). Biol Conserv 118:549-558

Nakagawa S, Möstl E, Waas JR (2003) Validation of an enzyme immunoassay to measure faecal glucocorticoid metabolites from Adélie penguins (Pygoscelis adeliae): a non-invasive tool for the measurement of stress? Polar Biol 26:491-493

Quillfeldt P, Möstl E (2003) Resource allocation in Wilson's stormpetrels (Oceanites oceanicus) determined by measurement of glucocorticoid excretion. Acta Ethol 5:115-122
Quillfeldt P, Strange IJ, Masello JF (2005) Escape decisions of incubating females and sex ratio of juveniles in the Upland goose Chloephaga picta. Ardea 93:171-178

Summers RW (1983) The life cycle of the Upland goose Chloëphaga picta in the Falkland Islands. Ibis 125:524-544

Summers RW, McAdam J (1993) The Upland goose. A study of the interaction between geese, sheep and man in the Falkland Islands. Bluntisham Books, Bluntisham

Tempel DJ, Gutiérrez RJ (2004) Factors related to faecal corticosterone levels in California spotted owls: implications for assessing chronic stress. Conserv Biol 18:538-547

Thiel D, Jenni-Eiermann S, Braunisch V, Palme R, Jenni L (2008) Ski tourism affects habitat use and evokes a physiological stress response in capercaillie Tetrao urogallus: a new methodological approach. J Appl Ecol 45:845-853

Walker BG, Boersma PD, Wingfield JC (2005) Field endocrinology and conservation biology. Integ Comp Biol 45:12-18

Wasser SK, Hunt KE, Brown JL, Cooper K, Crockett CM, Bechert U, Millspaugh Larson S, Monfort SL (2000) A generalized fecal glucocorticoid assay for use in a diverse array of nondomestic mammalian and avian species. Gen Comp Endocrinol 120:260-275

Watson A, Moss R (2004) Impact of ski-development on ptarmigan ( Lagopus mutus) at Cairn Gorm, Scotland. Biol Conserv 116:267-275 